Research article

\title{
Adrenaline modulates the global transcriptional profile of Salmonella revealing a role in the antimicrobial peptide and oxidative stress resistance responses

\author{
MH Karavolos ${ }^{1}$, H Spencer ${ }^{1}$, DM Bulmer ${ }^{1}$, A Thompson ${ }^{2}$, K Winzer ${ }^{3}$, \\ P Williams ${ }^{4}$, JCD Hinton ${ }^{2}$ and CM Anjam Khan*1
}

Address: ${ }^{1}$ Institute for Cell and Molecular Biosciences, The Medical School, University of Newcastle, Newcastle NE2 4HH, UK, ${ }^{2}$ Institute of Food Research, Norwich Research Park, Colney, Norwich NR4 7UA, UK, ${ }^{3}$ School for Health and Medicine, Division of Biomedical and Life Sciences, Lancaster University, Lancaster, LA1 4YQ, UK and ${ }^{4}$ Institute of Infection Immunity and Inflammation, University Park, University of Nottingham, Nottingham NG7 2RD, UK

Email: MH Karavolos - michail.karavolos@ncl.ac.uk; H Spencer - hannah.spencer@ncl.ac.uk; DM Bulmer - d.m.bulmer@ncl.ac.uk; A Thompson - arthur.thompson@bbsrc.ac.uk; K Winzer - k.winzer@lancaster.ac.uk; P Williams - paul.williams@nottingham.ac.uk; JCD Hinton - jay.hinton@bbsrc.ac.uk; CM Anjam Khan* - anjam.khan@ncl.ac.uk

* Corresponding author

Published: 6 October 2008

BMC Genomics 2008, 9:458

doi:|0.| | 86/|47|-2|64-9-458
Received: 4 June 2008

Accepted: 6 October 2008

This article is available from: http://www.biomedcentral.com/I47I-2/64/9/458

(c) 2008 Karavolos et al; licensee BioMed Central Ltd.

This is an Open Access article distributed under the terms of the Creative Commons Attribution License (http://creativecommons.org/licenses/by/2.0), which permits unrestricted use, distribution, and reproduction in any medium, provided the original work is properly cited.

\begin{abstract}
Background: The successful interaction of bacterial pathogens with host tissues requires the sensing of specific chemical and physical cues. The human gut contains a huge number of neurons involved in the secretion and sensing of a class of neuroendocrine hormones called catecholamines. Recently, in Escherichia coli O157:H7, the catecholamines adrenaline and noradrenaline were shown to act synergistically with a bacterial quorum sensing molecule, autoinducer 3 (Al-3), to affect bacterial virulence and motility. We wished to investigate the impact of adrenaline on the biology of Salmonella spp.

Results: We have determined the effect of adrenaline on the transcriptome of the gut pathogen Salmonella enterica serovar Typhimurium. Addition of adrenaline led to an induction of key metal transport systems within 30 minutes of treatment. The oxidative stress responses employing manganese internalisation were also elicited. Cells lacking the key oxidative stress regulator OxyR showed reduced survival in the presence of adrenaline and complete restoration of growth upon addition of manganese. A significant reduction in the expression of the pmrHFIJKLM antimicrobial peptide resistance operon reduced the ability of Salmonella to survive polymyxin B following addition of adrenaline. Notably, both phenotypes were reversed by the addition of the $\beta$-adrenergic blocker propranolol. Our data suggest that the BasSR two component signal transduction system is the likely adrenaline sensor mediating the antimicrobial peptide response.

Conclusion: Salmonella are able to sense adrenaline and downregulate the antimicrobial peptide resistance pmr locus through the BasSR two component signalling system. Through iron transport, adrenaline may affect the oxidative stress balance of the cell requiring OxyR for normal growth. Both adrenaline effects can be inhibited by the addition of the $\beta$-adrenergic blocker propranolol. Adrenaline sensing may provide an environmental cue for the induction of the Salmonella stress response in anticipation of imminent host-derived oxidative stress. However, adrenaline may also serve in favour of the host defences by lowering antimicrobial peptide resistance and hence documenting for the first time such a function for a hormone.
\end{abstract}




\section{Background}

Bacterial pathogens can sense a variety of physical and chemical niche-specific cues enabling them to physiologically adapt and modulate virulence to survive and cause disease. To enable successful host-pathogen interactions it is increasingly recognised that bacteria must also respond to a diverse range of host effector molecules. The term "microbial endocrinology" was first used to describe the interactions of microbes with the neuroendocrine environment of their host [1]. Catecholamine hormones like adrenaline and noradrenaline are released in the bloodstream and are involved in the regulation of a wide variety of host physiological processes. Current data suggests that catecholamines can induce DNA damage via production of hydroxyl radicals in the presence of iron [2]. More recently, adrenaline was implicated in the production of hydroxyl radicals in rat hepatocytes via an adrenoreceptor-mediated mechanism [3].

There is evidence that non-neural cells like peripheral human $\mathrm{T}$ lymphocytes contain and are able to synthesize catecholamines from normal precursors in physiologic concentrations [4,5]. Recently, bacterial lipopolysaccharide has been shown to induce production and release of adrenaline and noradrenaline by macrophages and neutrophils [6]. It was therefore suggested that the phagocytic system represents a diffusely expressed adrenergic organ [6].

Both adrenaline and noradrenaline are present in the gastrointestinal system where they mediate normal gut physiology [7]. During infection, plasma levels of catecholamines rise in an increase previously associated with the onset of infection [8]. There is evidence to suggest that general stress can alter levels of these hormones in the gut and could act as an environmental cue for pathogens $[8,9]$.

Indeed, catecholamines have been shown to induce both Gram negative and Gram positive bacterial growth via the provision of iron [10-15]. Noradrenaline affects production of the K99 pilus adhesin of enterotoxigenic Escherichia coli and also Shiga toxin in E. coli O157:H7 thus influencing the virulence fitness of these pathogens $[16,17]$.

Although catecholamines represent a eukaryotic cell signal to mediate a concerted organ function, bacteria utilise a different form of communication mediated by small molecules termed "autoinducers" in a process called "quorum sensing" [18-20]. Briefly, bacteria produce and sense autoinducers (AIs) in a concentration-dependent fashion. Upon achievement of a critical concentration of autoinducer, a signal is generated to regulate processes such as bioluminescence, antibiotic biosynthesis, plasmid conjugation, biofilm formation, DNA uptake competence, sporulation, and virulence [21-23]. Recently, a novel autoinducer, AI-3, produced by E. coli and other Gram negative bacteria was shown to act in synergy with adrenaline and noradrenaline to regulate E. coli genes involved in motility and virulence independently of enterobactin-mediated iron transport [24]. Furthermore, $\alpha$ adrenergic antagonists were able to block these interactions suggesting sensory transduction through common receptors [25].

In this report we dissect the global effects of adrenaline on the Salmonella enterica serovar Typhimurium (S. Typhimurium) transcriptome. Our data show that approximately $0.6 \%$ of the transcriptome of the pathogen is significantly regulated by adrenaline. Most of the genes affected represent those involved in transport but we also see alterations in genes encoding proteins of unknown functions. We also notice changes in levels of regulators and signal transduction genes.

The major feature of the $S$. Typhimurium adrenaline response is the upregulation of genes involved in metal homeostasis and oxidative stress. Prompted by the transcriptomic data we investigated the expression of the manganese superoxide dismutase $(\operatorname{sod} A)$, and the regulators of iron homeostasis (fur) and oxidative stress (oxyR). Our evidence suggests that adrenaline provides an environmental cue to alert $S$. Typhimurium against impending macrophage-derived peroxide stress as shown by the reduced ability of $S$. Typhimurium lacking OxyR to survive in the presence of adrenaline.

Furthermore we identified a downregulation of the pmrHFIJKLM operon which encodes a well characterised lipid A-modification system that provides resistance to the cationic antimicrobial peptide polymyxin $\mathrm{B}$. We investigated the expression of the pmr locus and suggest adrenalinemediated reduction in antimicrobial peptide resistance is mediated by the BasSR two component signal transduction system.

The fact that adrenaline provides an environmental cue that alerts the bacterial defences against oxidative stress as well as acting in favour of the host by inducing a reduction in bacterial antimicrobial peptide resistance is a unique combination. This finding represents a novel insight concerning the role of hormones in pathogen-host interactions.

\section{Methods \\ Bacterial Strains, Plasmids, and Growth Conditions}

S. enterica serovar Typhimurium strains and plasmids are shown in Table 1. Strains were grown overnight in $5 \mathrm{ml} \mathrm{LB}$ broth and $25 \mu$ l of the overnight culture were used to inoc- 
Table I: Strains plasmids and primers used in this study

\begin{tabular}{|c|c|c|}
\hline \multicolumn{3}{|l|}{ Strains } \\
\hline Name & Genotype & Reference \\
\hline SLI 344 & Parent strain & {$[73]$} \\
\hline SLI344oxyR & SLI344 $\Delta$ oxyR & This work \\
\hline SLI344fur & SLI344 $\Delta$ fur & This work \\
\hline SLI344sodA & SLI344 $\Delta$ sodA & This work \\
\hline SLI344basS & SLI344 $\Delta$ basS & This work \\
\hline SLI344pA & SLI344 (pMKI/ux-P & This work \\
\hline SLI344pM & $\mathrm{SLI} 344\left(\mathrm{pMK} \mid \mathrm{lux}-\mathrm{P}_{\mathrm{pmrH}}\right)$ & This work \\
\hline \multicolumn{3}{|l|}{ Plasmids } \\
\hline Name & Description & Reference \\
\hline pBR322 & Cloning vector & {$[74]$} \\
\hline pSB377 & lux $C D A B E$ reporter operon & {$[75]$} \\
\hline pMKIlux & pBR322 with luxCDABE operon and MCS & This work \\
\hline PMKI lux - $P_{\text {sodA }}$ & PMKIlux with $\mathrm{P}_{\text {sodA }}$ cloned as 5'EcoRI-3'BamHI fragment & This work \\
\hline pMKI I lux- $P_{\text {pmrH }}$ & pMKIlux with $\mathrm{P}_{\mathrm{pmrH}}$ cloned as 5'EcoRI-3'BamHI fragment & This work \\
\hline \multicolumn{3}{|l|}{ Primers } \\
\hline Name & Sequence & Comment \\
\hline sodA5 & GCGGAATTCATCAACAGGCG & cloning \\
\hline sodA3 & GCGGGATCCATTATTGTCGAGC & cloning \\
\hline pmr5 & CGCGAATTCGCGAAATAGCGTTTG & cloning \\
\hline pmr3 & CGCGGATCCATTGAAAGCCGCTTTTC & cloning \\
\hline pmr q5 & ATGTCGGACTTTTTGCCTTTC & qPCR \\
\hline pmr q3 & ATATTGATTGCCAGTTAGCC & qPCR \\
\hline sodA q5 & ATGAGTTATACACTGCCATC & qPCR \\
\hline $\operatorname{sodA~q3}$ & GCAAACTCAGGCAGGTTTTC & $\mathrm{qPCR}$ \\
\hline fhuA q5 & ATGGCGCGTCTTAAAACTGC & qPCR \\
\hline fhuA q3 & GCGGCAGGCGCTGCGGTTAC & qPCR \\
\hline invF q5 & ATGTCATTTTCTGAAAGCCG & qPCR \\
\hline invF q3 & AATGCCAGTAATTTGCTGAG & qPCR \\
\hline entE q5 & ATGCGTATACCTTTCACCCG & qPCR \\
\hline entE q3 & CTGAATGCGCGCTCGCCTTC & $\mathrm{qPCR}$ \\
\hline bas5 & CGCACGGTTCGCGGGTTTGG & $\lambda$-red \\
\hline bas3 & GTAGTGTGCTGATTGTCAGC & $\lambda$-red \\
\hline bas-PI & CTACATGCTGGTTGCCACTGAGGAAAGCTAAGTGAGCCTGGTGTAGGCTGGAGCTGCTTC & $\lambda$-red \\
\hline bas-P4 & AGTTTTATCTATGTGTGGGTCACGACGTATTAAACGCCTGATTCCGGGGATCCGTCGACC & $\lambda$-red \\
\hline fur5 & AGTGCAATTTCTGTCACTTC & $\lambda$-red \\
\hline fur3 & CAGGAAAGAGGAGGATATAA & $\lambda$-red \\
\hline fur-PI & TCTAATGAAGTGAATCGTTTAGCAACAGGACAGATTCCGCGTGTAGGCTGGAGCTGCTTC & $\lambda$-red \\
\hline fur-P4 & AAAAGCCAACCGGGCGGTTGGCTCTTCGAAAGATTTACACATTCCGGGGATCCGTCGACC & $\lambda$-red \\
\hline oxy5 & TAATCGTTCATTGCTATGCT & $\lambda$-red \\
\hline oxy3 & AACACCACCTTTAACTACCC & $\lambda$-red \\
\hline oxy-PI & ACCTATCGCCATGAACTATCGTGGCGACGGAGGATGAATAGTGTAGGCTGGAGCTGCTTC & $\lambda$-red \\
\hline oxy-P4 & TCGGGTTGCGGCGTTGAACGGCTTAAACCGCCTGTTTTAAATTCCGGGGATCCGTCGACC & $\lambda$-red \\
\hline
\end{tabular}

Restriction endonuclease sites are in bold.

ulate $25 \mathrm{ml}$ of $\mathrm{LB}$ in a $250 \mathrm{ml}$ conical flask at $37^{\circ} \mathrm{C}, 200$ $\mathrm{rpm}$. After $3.5 \mathrm{~h}$ growth $\left(\mathrm{OD}_{600^{\sim}} 1.0\right)$, adrenaline was added at a final concentration of $50 \mu \mathrm{M}$ from a fresh stock $(100 \mathrm{mM})$. Incubation was continued for an additional 30 minutes, cultures were harvested by centrifugation and
RNA extracted as described below. General physiological, molecular biological and protein manipulations were performed according to standard laboratory protocols $[26,27]$. Antibiotics were added to cultures at designated concentrations [27]. The gene content of strains used in 
transcriptomic experiments was confirmed by genomic indexing [28].

\section{Transcriptomics experimental design and methodology}

RNA was isolated from cultures according to protocols described on the IFR microarray web site http:www.ifr.ac.ufety/microarrays/protocolRNAextrac tionandpurifica tion.pdf. Briefly, two OD units of culture was fixed by incubation on ice with a $1 / 5$ culture volume of $5 \%$ phenol and 95\% ethanol to immediately stop RNA transcription or degradation. Cultures were centrifuged at 4,000 rpm for 10 minutes, and the resulting pellets were frozen at $80^{\circ} \mathrm{C}$. RNA was subsequently isolated using an SV Total RNA system (Promega) following the protocols provided by the manufacturer. The quality of the RNA was verified using an Agilent 2100 Bioanalyzer (Agilent), and the quantity was determined with an ND-1000 spectrophotometer (Nanodrop). Microarray hybridisation and scanning were performed at the Institute of Food Research, (IFR) Norwich as described previously $[28,29]$ and according to protocols described on the IFR microarray web site http:// www.ifr.ac.uk/safety/microarrays/\#protocols. Briefly, RNA samples $(16 \mu \mathrm{g})$ from three biological replicates and two technical replicates were labelled with Cy5-dCTP and hybridized to the IFR SALSA microarrays. Cy3-dCTP-labeled $S$. Typhimurium genomic DNA was used as a common reference in an indirect comparison type experimental design [30]. The IFR SALSA microarrays comprise 5080 genes from 5 different serovars of Salmonella http://www.ifr.ac.uk/safety/ microarrays/\#microarrays.

\section{Transcriptomics data analysis validation and in silico informatics}

Microarrays were scanned and fluorescence intensities quantified using GenePix Pro software, version 6.0 (Axon Instruments, Inc.). Microarray features showing a reference signal lower than background plus 2 standard deviations were discarded. Unequal dye incorporation was compensated by median centering (see http:// www.ifr.ac.uk/safety/microarrays/\#analysis). Transcriptomic data from adrenaline containing LB cultures was normalised to data from LB cultures without adrenaline and significant differences at $\mathrm{P} \leq 0.05$ were determined using a parametric-based statistical test by adjusting the individual P-value with the Benjamini and Hochberg false discovery rate multiple test correction [31]. All expression data for genes discussed in the text have passed this filter and are therefore statistically significant. These tests are features of the GeneSpring ${ }^{\mathrm{TM}} 7.2$ (Silicon Genetics) microarray analysis software package which was used for both data visualisation and analysis. The analysis was based on statistically significant differences displaying greater than 1.5 fold changes between LB cultures with and without adrenaline. In general transcriptomic data are filtered to only include equal to or greater than 2-fold differences, however less than 2-fold changes can also be biologically significant $[32,33]$.

Validation of microarray transcriptomic data was performed by quantitative RT-PCR (qPCR) analysis using the Qiagen QuantiTect SYBR Green system and a Roche Lightcycler 480. Primers used for validation analysis are listed in Table 1. Motif searches on protein sequences were carried out using "SMART" [34] and "PFAM" [35]. For protein homologies we used BLAST http://www.ncbi.nlm.nih.gov/blast/Blast.cgi.

\section{Construction of expression vectors}

The luxCDABE operon was amplified by PCR from pSB377 using primers $l u x 5$ and lux3 (Table 1). The PCR product containing an engineered multiple cloning site (MCS; EcoRI, SacI, KpnI, BamHI, XbaI, SnaBI) upstream of the lux operon was then EcoRI/EagI digested and ligated to EcoRI/EagI-cut pBR322 giving rise to pMK1lux. Promoters were cloned using the EcoRI and BamHI restriction sites of the MCS of pMK1lux. For a list of promoter primers and plasmid constructs see Table 1 .

Expression from promoter-lux transcriptional expression vectors was evaluated by growing $S$. Typhimurium containing the specific expression vector in $25 \mathrm{ml}$ of $\mathrm{LB}$ in a $250 \mathrm{ml}$ conical flask at $37^{\circ} \mathrm{C}, 200 \mathrm{rpm}$. After $3.5 \mathrm{~h}$ of growth adrenaline $(50 \mu \mathrm{M})$, propranolol $(500 \mu \mathrm{M})$, or water were added and incubation was continued for a further 30 minutes. Samples $(200 \mu \mathrm{l})$ were harvested, and the optical density and luminescence were determined with a Tecan Infinite200 spectrophotometer. Experiments were repeated at least three times.

\section{Adrenaline stress assay}

For determination of stress resistance during exposure to different adrenaline concentrations, bacteria were grown overnight in $5 \mathrm{ml} \mathrm{LB}$ broth and $25 \mu$ lof the overnight culture was used to inoculate $25 \mathrm{ml}$ of LB in a $250 \mathrm{ml}$ conical flask at $37^{\circ} \mathrm{C}, 200 \mathrm{rpm}$. After 3.5 hours growth $\left(\mathrm{OD}_{600} \sim 1.0\right)$, the following, or combinations were added; adrenaline $(50 \mu \mathrm{M})$, propranolol $(500 \mu \mathrm{M})$, manganese ( $5 \mathrm{mM}$ ) or water. Incubation was continued for an additional $3 \mathrm{~h}$, and serial dilutions were plated out on LB plates. Experiments were repeated at least three times and data are presented as survival numbers with standard error bars.

\section{Measurement of total Fe}

This was done as described by Velayudhan et al., (2007), with some modifications [36]. Bacteria were grown overnight in LB $(5 \mathrm{ml})$, then subcultured in $25 \mathrm{ml}$ fresh LB and grown at $37^{\circ} \mathrm{C}, 200 \mathrm{rpm}$ for $2 \mathrm{~h}$. Adrenaline $(50 \mu \mathrm{M})$, propranolol $(500 \mu \mathrm{M})$ or $\mathrm{H}_{2} \mathrm{O}$ was added and incubation was continued for an additional $4 \mathrm{~h}$. Cells were harvested, washed twice in $25 \mathrm{ml}$ of $10 \mathrm{mM}$ EDTA, pH 8.0 and twice 
in $25 \mathrm{ml}$ of analytical grade water (< 0.01p.p.m., Sigma). The $\mathrm{OD}_{600}$ and the volume of the cell suspension in the last wash were recorded. The final cell pellet was weighed and then solubilised by resuspending in $0.75 \mathrm{ml}$ of $30 \%$ ultra-pure nitric acid at $80^{\circ} \mathrm{C}$ for $16 \mathrm{~h}$. The volume was increased to $7 \mathrm{ml}$ with water before analysis by inductively coupled plasma atomic emission spectroscopy (ICP-AES) using a UNICAM 701 Series Emission Spectrometer (Chemical and Materials Analysis, Newcastle University). Five replicas per condition were carried out. Standard error bars are shown.

\section{Antimicrobial peptide assay}

Cells were evaluated for their ability to resist killing by the antimicrobial peptide polymyxin $\mathrm{B}$. This was done as described by Fields et al. (1989), with some modifications [37]. Bacteria exposed to adrenaline $(50 \mu \mathrm{M})$, propranolol $(500 \mu \mathrm{M})$ or water were aliquoted in a 96-well plate at a concentration of $2 \times 10^{4}$ to $5 \times 10^{4}$ bacteria per well, in 50 $\mu \mathrm{l}$ of a solution containing $0.5 \%$ tryptone and $0.5 \%$ sodium chloride. A $100 \mu \mathrm{l}$ volume of antimicrobial peptide was added (polymyxin B, $0.15 \mu \mathrm{g} \mathrm{ml}^{-1}$; Sigma) and the plate was incubated at $37^{\circ} \mathrm{C}, 150 \mathrm{rpm}$ for $1 \mathrm{~h}$. Samples were collected and viable counts performed by plating out different dilutions on LB plates. Data are presented as colony forming units and represent the average of three independent experiments.

Array Express; Accession Number E-MEXP-1738.

\section{Results and discussion Microarray Analysis of Salmonella Adrenaline Transcriptome}

During infection bacteria come into contact with a wide range of host-derived molecules ranging from very small molecular weight compounds to peptides and proteins. Adrenaline is produced by the host in specialised organ tissues [38]. Recently it was shown that phagocytes and polymorphonuclear cells are capable of de novo production of catecholamines, and when exposed to lipopolysaccharide in vitro they release noradrenaline and adrenaline [6]. These findings stimulated our interest in investigating the effects of adrenaline on S. enterica serovar Typhimurium. We used adrenaline at the concentration of $50 \mu \mathrm{M}$ to reflect experiments previously performed by others [24] and sampled at 30 minutes post-addition.

The transcriptomic data showed that the addition of adrenaline leads to a significant regulation $(\mathrm{P} \leq 0.05)$ of 25 genes with alterations ranging from 0.4 to 2.3 fold (Table 2). Interestingly, more that $52 \%$ of the adrenalineregulated genes were involved in transport and metabolism and approximately a third encoded proteins of unknown function (Fig 1).
The majority of the upregulated genes encoded components involved in iron transport, microcin, and oxidative stress resistance. Most of the genes displaying decreased expression levels belonged to the BasSR-regulated pmrHFIJKLM operon which encodes a lipid A modification system $[39,40]$.

Among the downregulated genes was $f l g D$, encoding a flagellar basal body rod modification protein, and $i n v F$, involved in Salmonella Pathogenicity Island 1 (SPI-1) mediated Type 3 secretion (T3S). We did not observe a significant difference in $S$. Typhimurium motility or the SPI1 mediated T3S secreted protein profile during exposure to adrenaline (data not shown). However in E. coli, studies performed to assess the role of catecholamines on the transcriptome have revealed significant changes in both motility and T3S genes $[41,42]$. This may reflect important biological differences between the two organisms under the conditions tested. In agreement with our observations these studies also identified upregulation of iron transport genes.

The transcriptomic results were validated by qPCR (Table 2) and also by the use of luminescent transcriptional reporters and a range of phenotypic screens. We constructed promoter transcriptional fusions to investigate the oxidative stress response using sodA (upregulated) and the antimicrobial peptide resistance pmr operon (downregulated) as described below.

\section{Transport systems affected by adrenaline in Salmonella}

The majority of adrenaline-regulated genes are involved in metal transport, uptake of siderophores and microcins (Table 2 and Fig. 2). fhuA and fhuC encode components of the hydroxamate-dependent iron transport system in Salmonella spp. and are also the receptors for microcin 25 [43]. Microcin J25 stimulates the production of reactive oxygen species such as superoxide ion $\left(\mathrm{O}_{2}^{-}\right)$in bacterial cells, leading to damage via perturbation of the membrane respiratory chain [44]. In E. coli the ferric hydroxamate uptake receptor FhuA transports siderophores in a TonB-dependent manner $[45,46]$. The exbBD system, participating in the TonB-dependent uptake of microcin J25 in E. coli and responsible for enterochelin and B colicin uptake [47] is also significantly upregulated. Induction of such systems may provide a valuable insight into the way adrenaline affects bacterial physiology to modulate hostpathogen interactions during infection.

Two additional systems involved in manganese, sit $A B$ and iron transport, $f e o A B,[48]$ are also upregulated by adrenaline. The sit $A B C D$ locus encodes an important transporter of manganese and iron which is required for resistance to $\mathrm{H}_{2} \mathrm{O}_{2}$ and for full virulence of $S$. Typhimurium in animals [49-51]. SitA is also required for Salmo- 
Table 2: Adrenaline regulated genes of $S$. Typhimurium

A

Adrenaline Upregulated genes

KEGG annotation Product

Fold change

Transport and metabolism

\begin{tabular}{lll}
\hline STM0192, fhuC & ATP-binding component of hydroxymate-dependent iron transport & $\mathbf{2 . 3}$ \\
STM3159, exbB & uptake of enterochelin; tonB-dependent uptake of B colicins & $\mathbf{2 . 2}$ \\
STM0191, fhuA & outer membrane protein receptor for ferrichrome & $\mathbf{2 . 0}$ \\
STM3158, exbD & uptake of enterochelin; tonB-dependent uptake of B colicins & $\mathbf{2 . 0}$ \\
STM0596,entE & 2,3-dihydroxybenzoate-AMP ligase & $\mathbf{I . 8}$ \\
STM3506, feoB & ferrous iron transport protein B & $\mathbf{1 . 8}$ \\
STM3505,feoA & ferrous iron transport protein A & $\mathbf{I . 8}$ \\
STM286I, sitA & fur regulated Salmonella Mn transporter \\
STM2862, sitB & fur regulated Salmonella Mn transporter \\
Oxidative Stress & & $\mathbf{1 . 6}$ \\
\hline STM4055, sodA & superoxide dismutase \\
Function unknown & & $\mathbf{1 . 5}$ \\
\hline STMI728, yciG & putative cytoplasmic protein \\
STM2263, yojl & putative ABC-type multidrug/protein/lipid transport system \\
STMI586 & putative periplasmic protein, similar to E. coli putative receptor \\
STMI729,yciF & putative cytoplasmic protein \\
\hline
\end{tabular}

\section{B}

Adrenaline Downregulated genes

KEGG annotation

Product

Fold change

Transport and metabolism

\begin{tabular}{lll}
\hline STM2299,yfbG $(p m r l)$ & transformylase & $\mathbf{0 . 4}$ \\
STMI 935, ftn & cytoplasmic ferritin & $\mathbf{0 . 4}$ \\
STM2297, yfbE $(p m r H)$ & 4-amino-4-deoxy-L-arabinose LPS-modifying enzyme & $\mathbf{0 . 5}$ \\
STM2298, pmrF & glycosyl transferase & $\mathbf{0 . 5}$ \\
Surface structure & &
\end{tabular}

\begin{tabular}{|c|c|}
\hline $\begin{array}{l}\text { STMII I6, flgD } \\
\text { SPII-5 }\end{array}$ & flagellar hook capping protein \\
\hline
\end{tabular}

STM2899, invF

invasion protein

0.6

Regulators, Signal Transduction

STM230I, pqaB (pmrK)

STM3216

Function unknown
STMI 936, yecH

STM4293, yjdB

STM2300, pmrJ polymyxin $B$ resistance

putative methyl-accepting chemotaxis protein II, aspartate sensor receptor
0.4

0.4

0.5

0.5

0.7

\section{C}

Microarray Validation

putative cytoplasmic protein 
Table 2: Adrenaline regulated genes of $S$. Typhimurium (Continued)

\begin{tabular}{|c|c|c|c|}
\hline \multirow[b]{2}{*}{ KEGG annotation } & \multirow[b]{2}{*}{ Product } & \multicolumn{2}{|c|}{ Fold change } \\
\hline & & Microarrays & qPCR \\
\hline STM0I9I, fhuA & outer membrane protein receptor for ferrichrome & 2.03 & 2.46 \\
\hline STM0596, entE & 2,3-dihydroxybenzoate-AMP ligase & 1.80 & 1.29 \\
\hline STM4055, sodA & superoxide dismutase & 1.90 & 1.18 \\
\hline STM2297, yfbE (pmrH) & 4-amino-4-deoxy-L-arabinose LPS-modifying enzyme & 0.45 & 0.45 \\
\hline STM2899, invF & invasion protein & 0.64 & 0.57 \\
\hline
\end{tabular}

nella spp. virulence in macrophages by facilitating manganese transport [52]. Bacterial accumulation of manganese forms the basis for an alternative catalytic detoxification of reactive oxygen species, the exact mechanism of which is not yet completely understood [53]. We hypothesise that intracellular manganese accumulation reflected an adrenaline-induced mechanism to aid pathogen survival. The downregulation of the $S$. Typhimurium $f t n$ gene encoding a ferritin involved in iron storage [54], may mirror the perturbation in the general metal pool during exposure to adrenaline.

The superoxide dismutase, sodA, gene is also significantly upregulated by adrenaline (Table 2 ). The $S$. Typhimurium manganese-cofactored superoxide dismutase (SodA) is involved in resistance to the early oxygen-dependent microbicidal mechanisms of phagocytes [55]. Using a luminescent $\operatorname{sodA}$ transcriptional reporter we observed a slight $(10 \%)$ but significant $(P \leq 0.05)$ increase in sodA expression supporting the transcriptomic results and also highlighting the presence of increased oxidative stress by exposure to adrenaline (Fig. 3). The effect was not blocked by addition of $\beta$-adrenergic blocker propranolol (Fig. 3). We used a $S$. Typhimurium strain lacking $\operatorname{sodA}$ (SL1344sodA) to further characterise the importance of the superoxide dismutase in the response to adrenaline. We did not observe a significant change in the numbers of bacteria surviving exposure to $50 \mu \mathrm{M}$ adrenaline when compared to the wild type SL1344, suggesting that sodA is not essential for survival during exposure to adrenaline (data not shown).

The above $S$. Typhimurium transcriptional signature suggests a dual role for adrenaline. On the one hand, by

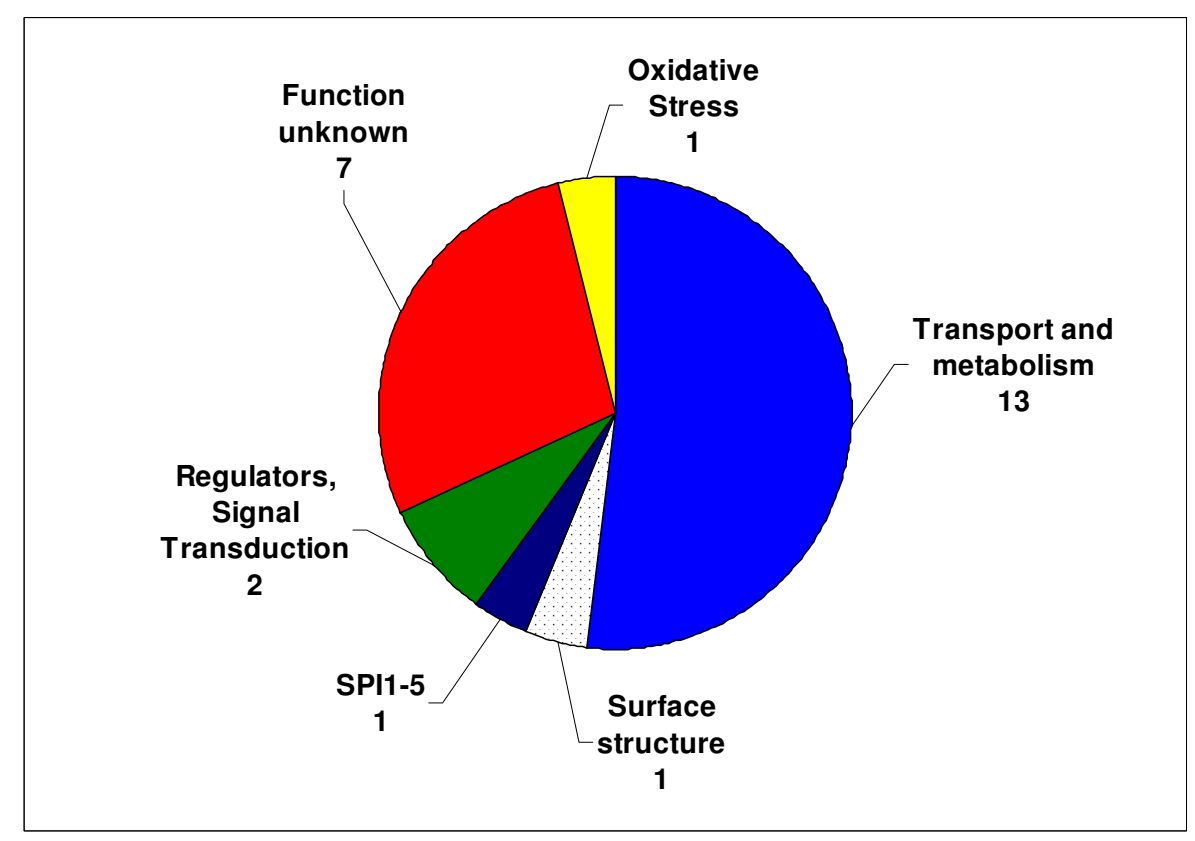

Figure I

The S. Typhimurium adrenaline-regulated transcriptome. Pie chart displaying number of genes in selected categories significantly altered upon addition of adrenaline $(50 \mu \mathrm{M})$. A detailed list of the genes can be found in Table 2 . 


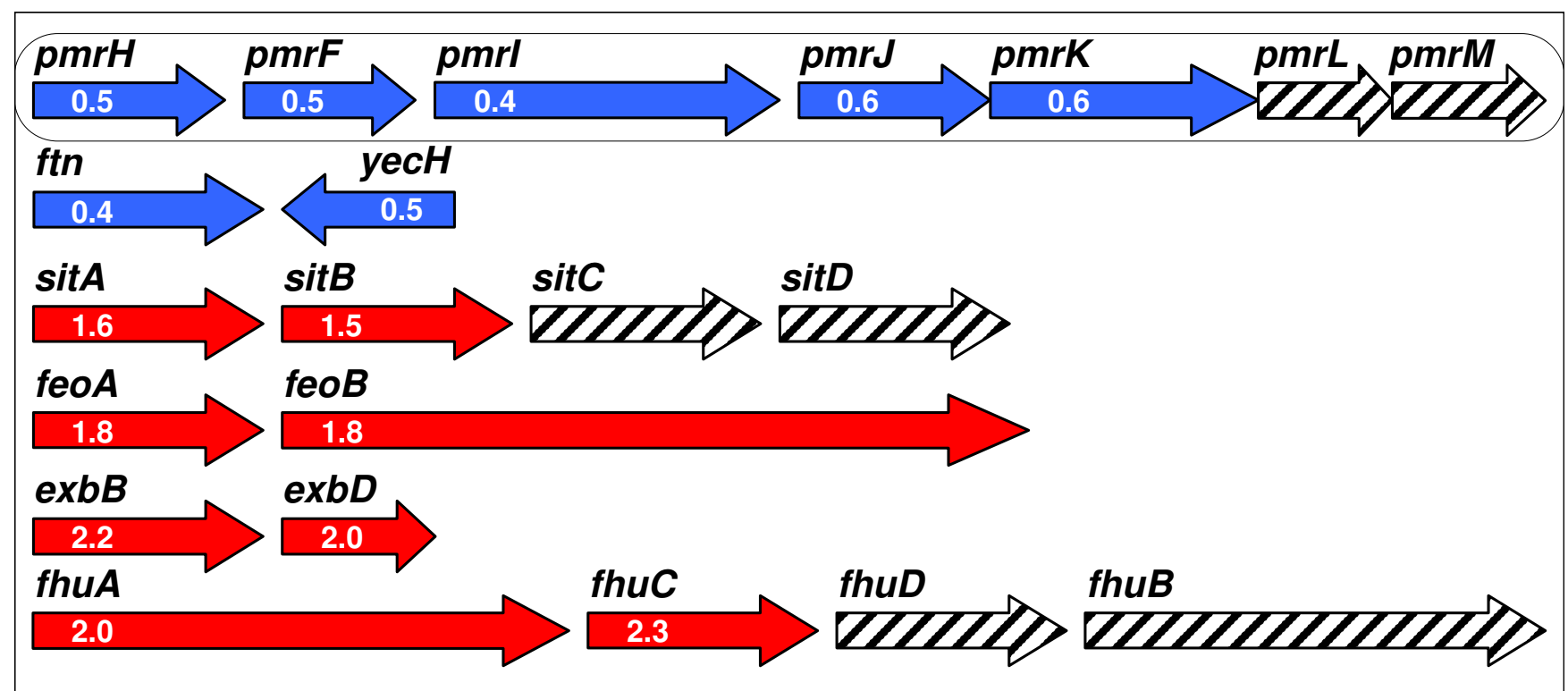

Figure 2

Diagrammatic representation of major operons affected by adrenaline. Chromosomal organisation of genes showing a significant transcriptional change upon addition of adrenaline $(50 \mu \mathrm{M})$. Respective fold change values in relation to the untreated control are displayed within the individual gene. Unaffected genes within an operon are represented by skewed lines.

inducing iron uptake systems, it serves as a warning probing the bacteria to adjust their metal ion transport in such a way as to resist looming oxidative stress but, on the other hand, facilitating increased susceptibility to microcin assault by increasing microcin $\mathrm{J} 25$ receptor content.

\section{OxyR and not Fur is essential for survival during adrenaline exposure}

Oxidative stress resistance in bacterial cells is mediated by enzymatic as well as non-enzymatic methods involving manganese $[53,56]$. OxyR is a positive regulator of a range of genes implicated in resistance to hydrogen peroxide $[56,57]$. Fur fine-tunes the regulation of iron homeostasis by controlling iron transport $[56,58]$. Having observed a significant upregulation of iron and manganese transporter genes by adrenaline, we examined the importance of fur and oxyR during Salmonella exposure to adrenaline. Exposure of SL1344 fur to $50 \mu \mathrm{M}$ adrenaline had no effect on its ability to grow in rich growth media suggesting furmediated functions are not important in the adrenaline response (data not shown). However, SL1344oxyR survived significantly less in the presence of adrenaline when compared to wild type SL1344 with the phenotype being blockable by the addition of the $\beta$-adrenergic blocker propranolol (Fig. 4A). To test if the effect was due to the ability of adrenaline to bind iron we treated SL1344oxyR with metanephrine, a natural methylated metabolite of adrenaline which is unable to bind iron [59]. Addition of $50 \mu \mathrm{M}$ metanephrine had no significant effect on the survival of
SL1344oxyR supporting the role of adrenaline-bound iron in reducing the viability of the strain (Fig. 4A).

\section{Manganese rescues oxy $R$ in the presence of adrenaline}

We tested the ability of manganese to improve survival of SL1344oxyR treated with adrenaline by supplementing the growth medium with the metal. Addition of $5 \mathrm{mM}$ manganese fully restored bacterial survival back to wild type levels in SL1344oxyR treated with $50 \mu \mathrm{M}$ adrenaline (Fig. 4A). The importance of manganese in alleviating the oxidative stress effect in cells is related to its ability to reduce the effects of the Fenton reaction involving intracellular iron [53]. By a mechanism not fully elucidated yet, manganese acts as a natural free radical detoxifying agent reacting with superoxide and also hydrogen peroxide.

Measurement of the total metal ion concentration in cells treated with $50 \mu \mathrm{M}$ adrenaline as well as in the oxyR strain supports the hypothesis that adrenaline induces oxidative stress by promoting an increase in the intracellular iron concentration (Fig. 4B). We observe a 4-fold increase in the total iron concentration of cells treated with $50 \mu \mathrm{M}$ adrenaline when compared to the water-treated control (Fig. 4B). Furthermore, addition of $\beta$-adrenergic blocker propranolol blocks the adrenaline-mediated increase in the total iron concentration (Fig. 4B). SL1344oxyR has significantly increased total iron and reduced total manganese concentration when compared to SL1344 (Fig. 4B, C). This fact in conjunction with the adrenaline-induced increase in intracellular iron may explain the reduced via- 


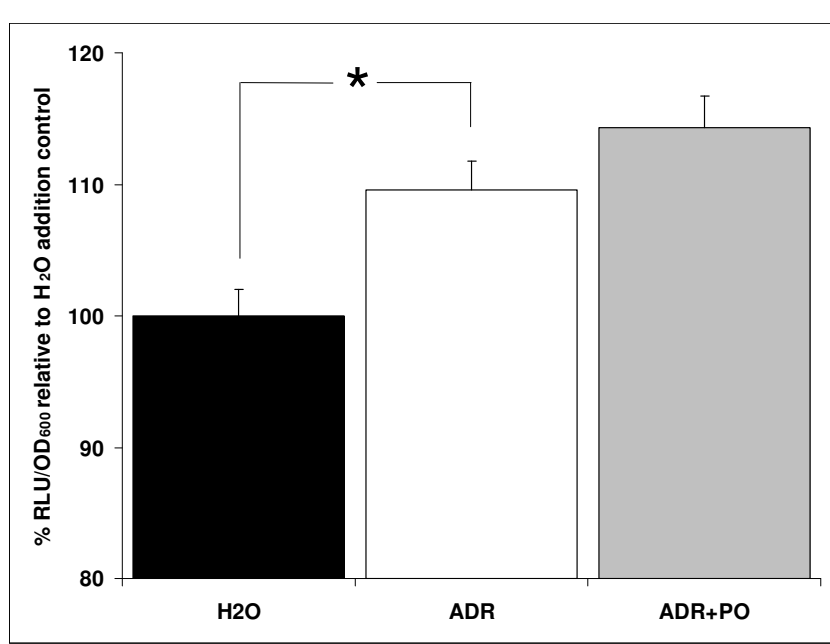

Figure 3

Adrenaline affects expression of sodA. A luminescent reporter fusion system ( $\mathrm{PMKI}$ lux- $\mathrm{P}_{\text {sodA }}$ ) was used to assess expression of the sodA gene during exposure to adrenaline. Exposure of SLI 344pA to adrenaline $(50 \mu \mathrm{M})$ for 30 minutes resulted in a significant $(10 \%)$ increase in sodA expression $(P$ $\leq 0.05$ ). Addition of $\beta$-adrenergic blocker propranolol (500 $\mu \mathrm{M})$ did not reverse the effect of adrenaline. Luminescence is expressed as a percentage of the water addition control in relative light units per culture optical density $\left(R L U / O D_{600}\right)$. Experiments were repeated at least three times. Asterisk indicates significant difference by the student t-test. Standard error bars are shown. Water, $\mathrm{H}_{2} \mathrm{O}$; Adrenaline, ADR; Propranolol, PO.

bility of SL1344oxyR upon adrenaline treatment and subsequent rescuing of viability with manganese (Fig. 4A). However, the role of propranolol in rescuing SL1344oxyR during exposure to adrenaline may be independent of manganese. This is highlighted by the reduction ( $\sim 2$ fold) in total manganese levels upon exposure to propranolol.

Adrenaline may therefore induce oxidative stress via an OxyR-dependent pathway in a manner reversible by the $\beta$ adrenergic blocker propranolol and also by the non-enzymatic manganese-based oxidative stress detoxification system.

\section{Adrenaline reduces expression of the pmr locus and increases sensitivity to polymyxin $B$}

Lipid A is a structural component of the lipopolysaccharide (LPS) in the outer membrane of Gram-negative bacteria and plays an important role in bacterial pathogenesis [60]. Polymyxin B, is a cationic antimicrobial peptide which binds to lipid A and damages the cell envelope [61]. Resistance to antimicrobial peptides has been shown to contribute to persistence of $S$. Typhimurium in a variety of niches ranging from the phagosomes within macro- phages to the C. elegans intestine $[62,63]$. The pmrHFI$J K L M$ operon encodes a set of proteins involved in lipopolysaccharide modification and resistance to the cationic antimicrobial polypeptide polymyxin $\mathrm{B}[64,65]$. The resistance mechanism involves attachment of phosphoethanolamine and 4-amino-4-deoxy-L-arabinose moieties on lipid A reducing its net negative charge and limiting its interaction with polymyxin $[39,66]$. In $S$. Typhimurium, the pmr locus is under the control of the BasSR two component system $[39,67]$.

To further elucidate the effect of adrenaline on the pmr operon we constructed a transcriptional reporter fusion driving expression of the luxCDABE operon under the control of the $p m r$ promoter. Addition of adrenaline significantly $(\mathrm{P} \leq 0.05)$ reduced expression from the pmr promoter mirroring the array results (Fig. 5). The transcriptional downregulation of the pmr locus by adrenaline was fully reversible by the $\beta$-adrenergic blocker propranolol (Fig. 5).

We hypothesised that a reduction in expression of the pmr locus would lead to increased sensitivity to the antimicrobial peptide polymyxin $\mathrm{B}$. We tested the effect of adrenaline on the ability of Salmonella to resist polymyxin B by incubating Salmonella exposed to water or adrenaline to the antimicrobial peptide as detailed in "Methods and Materials". Pre-treatment of Salmonella with $50 \mu \mathrm{M}$ adrenaline resulted in a significant reduction in bacterial survival during exposure to polymyxin B when compared to the water treated control (Fig. 6). The adrenaline-induced reduction in the ability of Salmonella to resist polymyxin B was also fully reversible by the $\beta$-adrenergic blocker propranolol (Fig. 5).

The above data show a direct and reversible reduction of bacterial antimicrobial peptide resistance by a mammalian hormone and hence a novel "antibacterial" role for adrenaline. However, we note that Salmonella may have adapted to this negative effect of adrenaline within mammalian hosts by increasing Lipid A deacylation and palmitoylation, thus favouring survival via reduced TLR-4 receptor-based bacterial signalling $[68,69]$.

\section{Adrenaline-induced sensitivity to polymyxin B may be mediated via the BasSR two component system} In enterohemorrhagic E. coli O157:H7 the QseBC two component system senses adrenaline and is required for full virulence in a rabbit animal model [70]. The E. coli response to adrenaline was shown to be blockable by an $\alpha$-adrenergic antagonist [70]. In $S$. Typhimurium the BasSR two component system controls expression of the $p m r$ locus and is implicated in the regulation of various other genes $[39,40,71]$. The identity at the amino acid level between the BasS and QseC sensor kinases is 31\% 


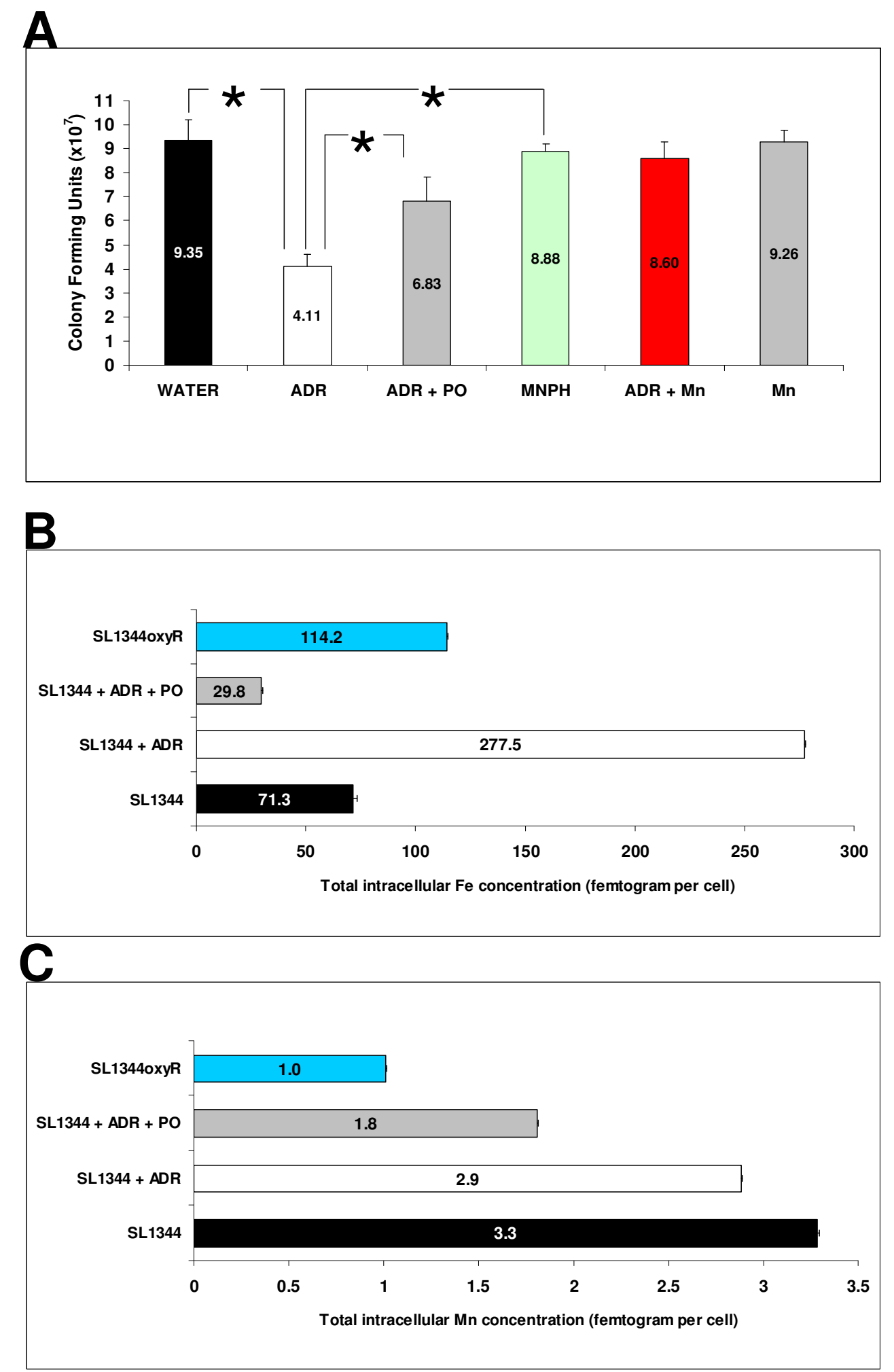

Figure 4 (see legend on next page) 
Figure 4 (see previous page)

OxyR and manganese are necessary for survival upon exposure to adrenaline. The role of the major oxidative stress regulator OxyR in the ability of Salmonella spp. to survive exposure to various adrenaline concentrations was assessed. (A) Deletion of oxyR in SLI344oxyR results in a dramatic loss of viability when exposed to adrenaline (50 $\mu M)$ for 30 minutes. The effect of adrenaline is significantly lessened by addition of propranolol (PO) at $500 \mu \mathrm{M}$. Addition of the adrenaline derivative metanephrine $(50 \mu \mathrm{M})$ which cannot bind iron has no significant effect on cell viability. Addition of manganese (5 mM) also fully counteracts the growth inhibition observed by adrenaline while the metal by itself (Mn) does not affect survival. SLI344 viability is unaffected by adrenaline (data not shown). (B) Measurement of total cell iron indicating a significant 4-fold increase upon exposure of SLI 344 to adrenaline, reduced levels upon simultaneous exposure to propranolol and adrenaline, and also significantly elevated levels in SLI344oxyR. (C) Measurement of total cell manganese indicating significantly reduced (3-fold) levels in SLI344oxyR and slightly reduced levels in SLI 344 upon addition of adrenaline or simultaneous exposure to propranolol and adrenaline. Experiments were repeated at least three times. Asterisk indicates significant difference by the student $t$-test. Standard error bars are shown. Adrenaline, ADR; Propranolol, PO; Metanephrine, MNPH; Manganese, Mn.

(over 270 amino acids; BLAST). Based on this similarity and also on the observed effects of adrenaline on the $p m r$ operon, we chose to further investigate the role of the sensory protein BasS in the mediation of the adrenaline response.

We constructed a S. Typhimurium SL1344 strain lacking the membrane sensor kinase BasS (SL1344basS) and tested its ability to survive polymyxin $B$ in the presence or absence of adrenaline. Survival of SL1344basS was signif-

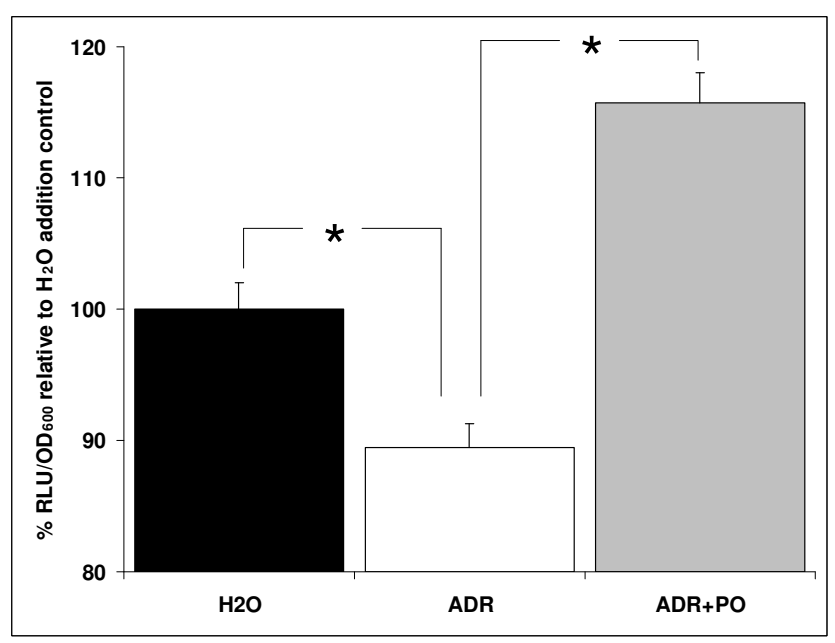

Figure 5

Expression of the pmr locus is reduced by adrenaline. Expression of the pmrHFIJKLM operon after a 30 minute exposure to adrenaline $(50 \mu \mathrm{M})$ was assessed in SL I 344pM by measuring luminescence per $\mathrm{OD}_{600}$ as described in "Methods". The significant transcriptional reduction ( $10 \% ; \mathrm{P} \leq 0.05)$ in expression was fully reversed by addition of $\beta$-adrenergic blocker propranolol $(500 \mu \mathrm{M})$. Luminescence is expressed as a percentage of the water addition control in relative light units per culture optical density $\left(\mathrm{RLU} / \mathrm{OD}_{600}\right)$. Experiments were repeated at least three times. Asterisk indicates significant difference by the student t-test. Standard error bars are shown. Water, $\mathrm{H}_{2} \mathrm{O}$; Adrenaline, ADR; Propranolol, PO. icantly reduced $(\mathrm{P} \leq 0.05)$ in the presence of polymyxin $\mathrm{B}$ due to downregulation of the pmr locus as previously published [67] (Fig. 6). Levels of polymyxin B resistance in water-treated SL1344basS were very similar to those observed in adrenaline-treated wild type SL1344. Furthermore, although addition of the $\beta$-adrenergic blocker propranolol significantly improved the survival of SL1344 to

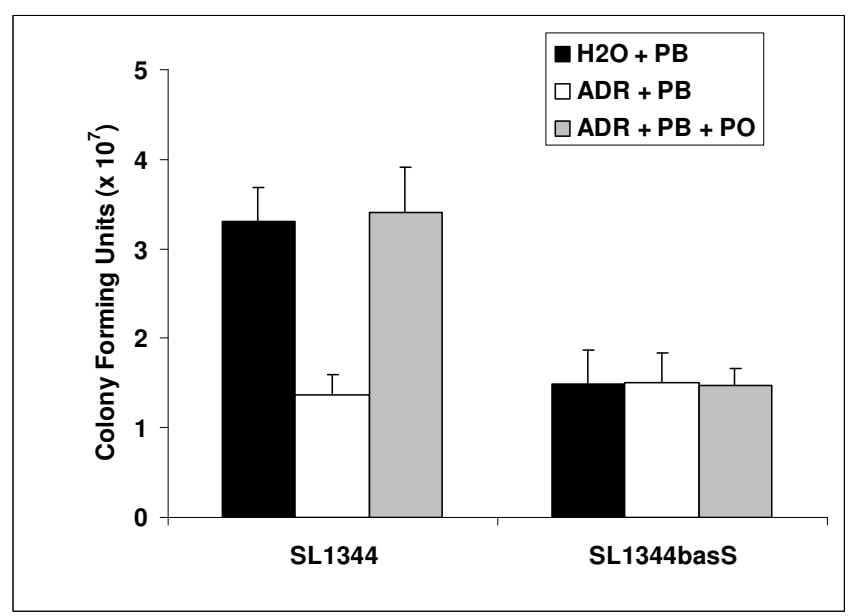

\section{Figure 6}

Adrenaline modulates the ability of Salmonella to resist antimicrobial peptides. We tested the effect of pre-exposure to adrenaline on the ability of Salmonella to resist the antimicrobial peptide polymyxin $B$. Addition of adrenaline $(50 \mu \mathrm{M})$ significantly reduced Salmonella survival during exposure to polymyxin $B\left(0.15 \mu \mathrm{g} \mathrm{ml}^{-1}\right)$. This was fully reversed by the $\beta$-adrenergic blocker propranolol (500 $\mu \mathrm{M})$. Sensitivity levels of the basS mutant (SLI 344basS) to polymyxin $B$ were very similar to those of the adrenaline-treated SL I 344. Reversal of polymyxin B sensitivity by propranolol is dependent on the presence of basS. Experiments were repeated at least three times. Asterisk indicates significant difference by the student $t$-test. Standard error bars are shown. Water, $\mathrm{H}_{2} \mathrm{O}$; Adrenaline, ADR; Polymyxin B, PB; Propranolol, PO. 
polymyxin B during exposure to adrenaline, survival of SL1344basS remained unaffected by the $\beta$-adrenergic blocker (Fig. 6).

The above data support the hypothesis that adrenaline exerts its effect on the pmr locus via the reversible interaction of the $\beta$-adrenergic blocker with the BasS membrane sensor in a manner similar to the interaction of adrenaline with QseC in E. coli. The low (31\%) amino acid sequence identity between BasS and QseC may provide a clue as to why we observe $\beta$-blockage in Salmonella as opposed to $\alpha$ blockage in E. coli.

\section{Conclusion}

Bacterial-host communication is increasingly being recognised as important in determining the outcome of infection. It is clear that bacterial pathogens encounter a wide range of host milieus, within which they must survive to successfully colonise and cause disease. Salmonella can replicate and survive within the harsh environment of the macrophage $[37,72]$. Our transcriptomic approach has revealed the response of Salmonella to adrenaline highlighting its dual role in mediating host-bacterial interactions. Systemic or macrophage produced adrenaline may therefore regulate the fine balance between the host and Salmonella defence mechanisms, and impact upon the development of disease.

\section{Authors' contributions}

MHK and CMAK conceived the study. All authors played a role in designing the laboratory experiments and analyzing the data. Microarray experiments were conducted by MHK and also AT. The microarray validations, reporter constructions, and phenotypic screens were conducted largely by MHK, with the exception of the following: HS constructed the oxyR and fur mutant strains and conducted the respective adrenaline sensitivity tests; $\mathrm{DMB}$ constructed the basS mutant. The research was coordinated by CMAK. MHK drafted the initial manuscript with important subsequent contributions and revisions from PW, KW, JCDH, and CMAK. All authors have read and approved the final manuscript.

\section{Acknowledgements}

We thank Mark Alston (Institute of Food Research, Norwich), Joe Gray (PINNACLE, Newcastle University), Daniel Swan (Bioinformatics Support Unit, Newcastle University) and Dave Dunbar (Chemical and Materials Analysis Services, Newcastle University) for helpful technical advice. We are also grateful to Brian Ahmer (Ohio State University) for providing expression vectors. This work was supported by Medical Research Council (MRC) and Biotechnology and Biological Sciences Research Council (BBSRC) research grants to C.M.A.K. and P.W., and a BBSRC core strategic grant to J.C.D.H. In addition, H.S. was a recipient of a BBSRC DTA PhD studentship with C.M.A.K.

\section{References}

I. Lyte M: Microbial endocrinology and infectious disease in the 2 I st century. Trends in Microbiology 2004, I 2: | 4-20.

2. Miura T, Muraoka S, Fujimoto $Y$, Zhao K: DNA damage induced by catechol derivatives. Chemico-Biological Interactions 2000, I 26: $125-136$.

3. Castrejon-Sosa M, Villalobos-Molina R, Guinzberg R, Pina E: Adrenaline (via [alpha] IB-adrenoceptors) and ethanol stimulate $\mathrm{OH}$ [radical sign] radical production in isolated rat hepatocytes. Life Sciences 2002, 7 I:2469-2474.

4. Bergquist J, Tarkowski A, Ekman R, Ewing A: Discovery of Endogeneous Catecholamines in Lymphocytes and Evidence for Catecholamine Regulation of Lymphocyte Function via an Autocrine Loop. PNAS 1994, 91:12912-12916.

5. Musso NR, Brenci S, Setti M, Indiveri F, Lotti G: Catecholamine content and in vitro catecholamine synthesis in peripheral human lymphocytes. J Clin Endocrinol Metab 1996, 81:3553-3557.

6. Flierl MA, Rittirsch D, Nadeau BA, Chen AJ, Sarma JV, Zetoune FS, McGuire SR, List RP, Day DE, Hoesel LM, et al.: Phagocyte-derived catecholamines enhance acute inflammatory injury. Nature 2007, 449:721-725.

7. Furness JB: Types of neurons in the enteric nervous system. Journal of the Autonomic Nervous System 2000, 8 I:87-96.

8. Jones SB, Westfall MV, Sayeed MM: Plasma catecholamines during $\mathbf{E}$. coli bacteremia in conscious rats. Am J Physiol Regul Integr Comp Physiol 1988, 254:R470-R477.

9. Goldberg AD, Becker LC, Bonsall R, Cohen JD, Ketterer MW, Kaufman PG, Krantz DS, Light KC, McMahon RP, Noreuil T, et al.: Ischemic, Hemodynamic, and Neurohormonal Responses to Mental and Exercise Stress: Experience From the Psychophysiological Investigations of Myocardial Ischemia Study (PIMI). Circulation 1996, 94:2402-2409.

10. Burton CL, Chhabra SR, Swift S, Baldwin TJ, Withers H, Hill SJ, Williams P: The Growth Response of Escherichia coli to Neurotransmitters and Related Catecholamine Drugs Requires a Functional Enterobactin Biosynthesis and Uptake System. Infect Immun 2002, 70:5913-5923.

II. Freestone PPE, Haigh RD, Williams PH, Lyte M: Stimulation of bacterial growth by heat-stable, norepinephrine- induced autoinducers. Fems Microbiology Letters 1999, I 72:53-60.

12. Freestone PPE, Lyte M, Neal CP, Maggs AF, Haigh RD, Williams PH: The mammalian neuroendocrine hormone norepinephrine supplies iron for bacterial growth in the presence of transferrin or lactoferrin. Journal of Bacteriology 2000, I 82:609|-6098.

13. Freestone PP, Williams PH, Haigh RD, Maggs AF, Neal CP, Lyte M: Growth stimulation of intestinal commensal Escherichia coli by catecholamines: A possible contributory factor in trauma- induced sepsis. Shock 2002, I 8:465-470.

14. Freestone PPE, Haigh RD, Williams PH, Lyte M: Involvement of enterobactin in norepinephrine-mediated iron supply from transferrin to enterohaemorrhagic Escherichia coli. Fems Microbiology Letters 2003, 222:39-43.

15. Lyte M, Freestone PPE, Neal CP, Olson BA, Haigh RD, Bayston R, Williams PH: Stimulation of Staphylococcus epidermidis growth and biofilm formation by catecholamine inotropes. Lancet 2003, 36 I: 130-135.

16. Lyte M, Arulanandam BP, Frank CD: Production of Shiga-like toxins by Escherichia coli O I 57:H7 can be influenced by the neuroendocrine hormone norepinephrine. Journal of Laboratory and Clinical Medicine 1996, I 28:392-398.

17. Lyte M, Erickson AK, Arulanandam BP, Frank CD, Crawford MA, Francis DH: Norepinephrine-induced expression of the K99 pilus adhesin of enterotoxigenic Escherichia coli. Biochemical and Biophysical Research Communications 1997, 232:682-686.

18. Williams P, Bainton NJ, Swift S, Chhabra SR, Winson MK, Stewart GSAB, Salmond GPC, Bycroft BW: Small Molecule-Mediated Density-Dependent Control of Gene- Expression in Prokaryotes - Bioluminescence and the Biosynthesis of Carbapenem Antibiotics. Fems Microbiology Letters 1992, 100:161-167.

19. Bassler BL, Wright M, Showalter RE, Silverman MR: Intercellular Signaling in Vibrio-Harveyi - Sequence and Function of Genes Regulating Expression of Luminescence. Molecular Microbiology 1993, 9:773-786.

20. Kaplan HB, Greenberg EP: Diffusion of Autoinducer Is Involved in Regulation of the Vibrio-Fischeri Luminescence System. Journal of Bacteriology 1985, 163:1210-1214. 
21. Greenberg EP: Bacterial communication and group behavior Journal of Clinical Investigation 2003, I I 2: I288- 2290.

22. Winzer K, Williams P: Quorum sensing and the regulation of virulence gene expression in pathogenic bacteria. International Journal of Medical Microbiology 200I, 29 I:I3I-I43.

23. Taga ME, Bassler BL: Chemical communication among bacteria. Proceedings of the National Academy of Sciences of the United States of America 2003, 100: I 4549- I 4554.

24. Sperandio V, Torres AG, Jarvis B, Nataro JP, Kaper JB: Bacteriahost communication: The language of hormones. Proceedings of the National Academy of Sciences of the United States of America 2003 100:895I-8956.

25. Clarke MB, Hughes DT, Zhu C, Boedeker EC, Sperandio V: The QseC sensor kinase: A bacterial adrenergic receptor. PNAS 2006, 103:10420-10425.

26. Karavolos MH, Wilson M, Henderson J, Lee JJ, Khan CMA: Type III secretion of the Salmonella effector protein SopE is mediated via an $\mathbf{N}$-terminal amino acid signal and not an mRNA sequence. Journal of Bacteriology 2005, I87:1559-1567.

27. Sambrook J, FEFMT: Molecular cloning: A laboratory Mannual N Y: Cold Spring Harbour laboratory Press; 1989.

28. Clements MO, Eriksson S, Thompson A, Lucchini S, Hinton JCD, Normark S, Rhen M: Polynucleotide phosphorylase is a global regulator of virulence and persistency in Salmonella enterica. Proceedings of the National Academy of Sciences of the United States of America 2002, 99:8784-8789.

29. Ygberg SE, Clements MO, Rytkonen A, Thompson A, Holden DW, Hinton JCD, Rhen M: Polynucleotide Phosphorylase Negatively Controls spv Virulence Gene Expression in Salmonella enterica. Infect Immun 2006, 74: I 243- I254.

30. Yang YH, Speed T: Design issues for cDNA microarray experiments. Nat Rev Genet 2002, 3:579-588.

31. Benjamini Y, Hochberg Y: Controlling the False Discovery Rate: A Practical and Powerful Approach to Multiple Testing. Journal of the Royal Statistical Society Series B (Methodological) 1995, 57:289-300

32. Hughes TR, Roberts C], Dai H, Jones AR, Meyer MR, Slade D, Burchard J, Dow S, Ward TR, Kidd MJ, et al.: Widespread aneuploidy revealed by DNA microarray expression profiling. Nat Genet 2000, 25:333-337.

33. Ichikawa JK, Norris A, Bangera MG, Geiss GK, 't Wout AIB, Bumgarner RE, Lory S: Interaction of Pseudomonas aeruginosa with epithelial cells: Identification of differentially regulated genes by expression microarray analysis of human cDNAs. Proceedings of the National Academy of Sciences of the United States of America 2000, 97:9659-9664.

34. Letunic I, Copley RR, Pils B, Pinkert S, Schultz J, Bork P: SMART 5: domains in the context of genomes and networks. Nucl Acids Res 2006, 34:D257-D260.

35. Bateman A, Coin L, Durbin R, Finn RD, Hollich V, Griffiths-Jones S, Khanna A, Marshall M, Moxon S, Sonnhammer ELL, et al.: The Pfam protein families database. Nucl Acids Res 2004, 32:DI 38-DI4I.

36. Velayudhan J, Castor M, Richardson A, Main-Hester KL, Fang FC: The role of ferritins in the physiology of Salmonella enterica sv. Typhimurium: a unique role for ferritin $B$ in iron-sulphur cluster repair and virulence. Molecular Microbiology 2007 63:1495-1507.

37. Fields PI, Groisman EA, Heffron F: A Salmonella locus that controls resistance to microbicidal proteins from phagocytic cells. Science 1989, 243:1059-1062.

38. Goldstein DS, Eisenhofer G, Kopin IJ: Sources and Significance of Plasma Levels of Catechols and Their Metabolites in Humans. J Pharmacol Exp Ther 2003, 305:800-8II.

39. Gunn JS, Lim KB, Krueger J, Kim K, Guo L, Hackett M, Miller SI: PmrA-PmrB-regulated genes necessary for 4-aminoarabinose lipid A modification and polymyxin resistance. Molecular Microbiology 1998, 27: II7|-II82.

40. Gunn JS, Ryan SS, Van Velkinburgh JC, Ernst RK, Miller SI: Genetic and Functional Analysis of a PmrA-PmrB-Regulated Locus Necessary for Lipopolysaccharide Modification, Antimicrobial Peptide Resistance, and Oral Virulence of Salmonella enterica Serovar Typhimurium. Infect Immun 2000, 68:6139-6I46.

4I. Kendall MM, Rasko DA, Sperandio V: Global Effects of the Cellto-Cell Signaling Molecules Autoinducer-2, Autoinducer-3, and Epinephrine in a luxS Mutant of Enterohemorrhagic Escherichia coli. Infect Immun 2007, 75:4875-4884.

42. Dowd Scot E: Escherichia coli O 157:H7 gene expression in the presence of catecholamine norepinephrine. Fems Microbiology Letters 2007, 273:2/4-223.

43. Destoumieux-Garzon D, Duquesne S, Peduzzi J, Goulard C, Desmadril M, Letellier L, Rebuffat S, Boulanger P: The ironsiderophore transporter FhuA is the receptor for the antimicrobial peptide microcin J25: role of the microcin Vall IProl6 beta-hairpin region in the recognition mechanism. Biochem J 2005, 389:869-876

44. Bellomio A Vincent PA de Arcuri BF, Farias RN, Morero RD: Microcin J25 Has Dual and Independent Mechanisms of Action in Escherichia coli: RNA Polymerase Inhibition and Increased Superoxide Production. J Bacteriol 2007, 189:4I 80-4I86.

45. Eisenhauer HA, Shames S, Pawelek PD, Coulton JW: Siderophore Transport through Escherichia coli Outer Membrane Receptor FhuA with Disulfide-tethered Cork and Barrel Domains. J Biol Chem 2005, 280:30574-30580.

46. Carter DM, Gagnon JN, Damlaj M, Mandava S, Makowski L, Rodi DJ, Pawelek PD, Coulton JW: Phage Display Reveals Multiple Contact Sites between FhuA, an Outer Membrane Receptor of Escherichia coli, and TonB. Journal of Molecular Biology 2006 357:236-25I

47. Vincent PA, Delgado MA, Farias RN, Salomon RA: Inhibition of Salmonella enterica serovars by microcin J25. Fems Microbiology Letters 2004, 236:103-107.

48. Cartron M, Maddocks S, Gillingham P, Craven C, Andrews S: FeoTransport of Ferrous Iron into Bacteria. BioMetals 2006, 19:143-157.

49. Boyer E, Bergevin I, Malo D, Gros P, Cellier MFM: Acquisition of Mn(II) in Addition to Fe(II) Is Required for Full Virulence of Salmonella enterica Serovar Typhimurium. Infect Immun 2002, 70:6032-6042.

50. Sabri M, Leveille S, Dozois CM: A SitABCD homologue from an avian pathogenic Escherichia coli strain mediates transport of iron and manganese and resistance to hydrogen peroxide. Microbiology 2006, I52:745-758.

5I. Kehres DG, Janakiraman A, Slauch JM, Maguire ME: SitABCD Is the Alkaline Mn2+ Transporter of Salmonella enterica Serovar Typhimurium. J Bacteriol 2002, 184:3159-3166.

52. Zaharik ML, Cullen VL, Fung AM, Libby SJ, Kujat Choy SL, Coburn B, Kehres DG, Maguire ME, Fang FC, Finlay BB: The Salmonella enterica Serovar Typhimurium Divalent Cation Transport Systems MntH and SitABCD Are Essential for Virulence in an Nramp IG 169 Murine Typhoid Model. Infect Immun 2004, 72:5522-5525.

53. Horsburgh MJ, Wharton SJ, Karavolos M, Foster SJ: Manganese: elemental defence for a life with oxygen. Trends in Microbiology 2002, 10:496-50I.

54. Andrews SC, Smith JMA, Yewdall SJ, Guest JR, Harrison PM: Bacterioferritins and ferritins are distantly related in evolution Conservation of ferroxidase-centre residues. FEBS Letters 1991, 293:164-168

55. Tsolis RM, Baumler AJ, Heffron F: Role of Salmonella typhimurium Mn-superoxide dismutase (SodA) in protection against early killing by $\mathbf{J 7 7 4}$ macrophages. Infect Immun 1995, 63:1739-1744.

56. Imlay JA: Cellular Defenses against Superoxide and Hydrogen Peroxide. Annual Review of Biochemistry 2008, 77:755-776.

57. Christman MF, Storz G, Ames BN: OxyR, a Positive Regulator of Hydrogen Peroxide-Inducible Genes in Escherichia coli and Salmonella typhimurium, is Homologous to a Family of Bacterial Regulatory Proteins. PNAS 1989, 86:3484-3488.

58. Kadner RJ: Regulation by Iron: RNA Rules the Rust. J Bacteriol 2005, I 87:6870-6873

59. Burton CL, Chhabra SR, Swift S, Baldwin TJ, Withers H, Hill SJ, Williams P: The Growth Response of Escherichia coli to Neurotransmitters and Related Catecholamine Drugs Requires a Functional Enterobactin Biosynthesis and Uptake System. Infect Immun 2002, 70:5913-5923.

60. Beutler B, Rietschel ET: Innate immune sensing and its roots: the story of endotoxin. Nat Rev Immunol 2003, 3:169-176.

61. Vaara M: Agents that increase the permeability of the outer membrane. Microbiol Mol Biol Rev 1992, 56:395-4II. 
62. Prost LR, Sanowar S, Miller SI: Salmonella sensing of anti-microbial mechanisms to promote survival within macrophages. Immunological Reviews 2007, 2 1 9:55-65.

63. Alegado RA, Tan MW: Resistance to antimicrobial peptides contributes to persistence of Salmonella typhimurium in the C. elegans intestine. Cellular Microbiology 2000, 0:

64. Noland BW, Newman JM, Hendle J, Badger J, Christopher JA, Tresser J, Buchanan MD, Wright TA, Rutter ME, Sanderson WE, et al:: Structural Studies of Salmonella typhimurium ArnB (PmrH) Aminotransferase: A 4-Amino-4-Deoxy-L-Arabinose Lipopolysaccharide-Modifying Enzyme. Structure 2002, 10:1569-1580

65. Yan A, Guan Z, Raetz CRH: An Undecaprenyl Phosphate-Aminoarabinose Flippase Required for Polymyxin Resistance in Escherichia coli. J Biol Chem 2007, 282:36077-36089.

66. Zhou Z, Ribeiro AA, Lin S, Cotter RJ, Miller SI, Raetz CRH: Lipid A Modifications in Polymyxin-resistant Salmonella typhimurium. PmrA-Dependent 4-Amino-4-Deoxy-L-Aabinose, and Phosphoethanolamine Incorporation. J Biol Chem 200I, 276:43|||-43|2|

67. Daisuke Hagiwara, Takeshi Mizuno, Takafumi Yamashino: A Genome-Wide View of the Escherichia coli BasS-BasR Twocomponent System Implicated in Iron-responses. Bioscience, Biotechnology, and Biochemistry 2004, 68: I758-I 767.

68. Kawasaki K, Ernst RK, Miller SI: Deacylation and palmitoylation of lipid $A$ by Salmonellae outer membrane enzymes modulate host signaling through Toll-like receptor 4. Journal of Endotoxin Research 2004, 10:439-444.

69. Kawasaki K, Ernst RK, Miller SI: Inhibition of Salmonella enterica Serovar Typhimurium Lipopolysaccharide Deacylation by Aminoarabinose Membrane Modification. J Bacteriol 2005, I 87:2448-2457.

70. Clarke MB, Hughes DT, Zhu C, Boedeker EC, Sperandio V: The QseC sensor kinase: A bacterial adrenergic receptor. PNAS 2006, I03: 10420-10425.

7I. Marchal K, De Keersmaecker S, Monsieurs P, van Boxel N, Lemmens K, Thijs G, Vanderleyden J, De Moor B: In silico identification and experimental validation of PmrAB targets in Salmonella typhimurium by regulatory motif detection. Genome Biology 2004, 5:R9.

72. Fields PI, Swanson RV, Haidaris CG, Heffron F: Mutants of Salmonella typhimurium That Cannot Survive within the Macrophage are Avirulent. PNAS 1986, 83:5189-5193.

73. Hoiseth SK, Stocker BAD: Aromatic-Dependent SalmonellaTyphimurium Are Non-Virulent and Effective As Live Vaccines. Nature 1981, 291:238-239.

74. Sutcliffe JG: Complete nucleotide sequence of the Escherichia coli plasmid pBR322. Cold Spring Harbour Symposium on Quantitative Biology 1979, 43:77-90.

75. Winson MK, Swift S, Hill PJ, Sims CM, Griesmayr G, Bycroft BW, Williams $P$, Stewart GSAB: Engineering the luxCDABE genes from Photorhabdus luminescens to provide a bioluminescent reporter for constitutive and promoter probe plasmids and mini-Tn5 constructs. Fems Microbiology Letters 1998, 163:193-202.
Publish with Biomed Central and every scientist can read your work free of charge

"BioMed Central will be the most significant development for disseminating the results of biomedical research in our lifetime."

Sir Paul Nurse, Cancer Research UK

Your research papers will be:

- available free of charge to the entire biomedical community

- peer reviewed and published immediately upon acceptance

- cited in PubMed and archived on PubMed Central

- yours - you keep the copyright
BiolMedcentral 